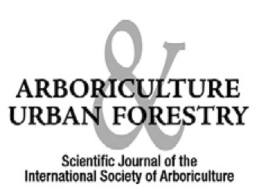

\title{
Editorial Response
}

\section{FATALITIES AND INJURIES CAUSED BY TREES: DO WE HAVE A PROBLEM?}

Julian Dunster

Concerns about tree risk are increasingly common. High profile news reports about trees killing or injuring people in the United Kingdom, Australia, and North America are common. Responses range from, "It was an act of god," through to, "We repeatedly said it would fail." In the United States, courts have imposed multimillion dollar settlements on tree owners.

In the United Kingdom, several judgments have caused tree owners to fell the trees rather than manage the risk. A tree fatality in British Columbia, Canada, led to the creation of the Certified Tree Risk Assessor accreditation, which launched in 2005. The program was specifically developed to respond to a concern of WorkSafe British Columbia (the government agency charged with enforcing the Occupational Health and Safety Regulations) regarding tree risk issues and worker safety. The Tree Risk Assessment Course and Exam (TRACE) was the first such course in North America. This course and credential lead to the ISA Tree Risk Assessment Qualification (TRAQ), which launched in 2013. Other risk assessment schemes and courses, such as Quantified Tee Risk Assessment (QTRA) and Tree Hazard: Risk Evaluation and Treatment System (THREATS), have evolved in the United Kingdom. TRACE, TRAQ, and the ISA's Best Management Practices booklet for tree risk assessment have raised the standard of care for tree risk assessments. As a result, more arborists are aware of the need for tree risk assessment and tree owners are undertaking risk assessment and risk management in a more diligent manner. All of this is surely a positive step forward, but will it affect the number of people killed or injured by tree failures?
Perceptions about tree risk issues vary widely. Some people may simply feel threatened by trees regardless of the risk issues. Others may feel that the tree failure incidents are extremely rare, and overall risk is low. Therefore, it is argued, it is not justifiable to spend a lot of money dealing with tree risk issues. The reality may be different, but until recently, there were few if any continuously updated databases in many parts of the world to show just how extensive the problem might be.

In order to better understand the magnitude of tree failure incidents, where tree failures kill or injure people, a more global documentation project was initiated in 2007, testing a series of Englishlanguage Google Alerts $^{\mathrm{rn}}$ word combinations. Once the word combinations were refined, a more comprehensive database of incidents from around the world was started in 2008, and is ongoing. (The data relies on reports published in, or translated to English. It is entirely possible that the numbers of incidents documented would be higher around the world if all language reports were included.) The intent is to document order of magnitude estimates about how many people are actually killed or injured by trees. The data do not deal with tree workers within or near the trees. Rather, the data collected concerns people who have no direct connection with the tree-people walking, cycling, or driving by in their homes or backyards, or using trails in parks. There is no distinction in the data between trees on public versus private land.

There are constraints on the data. It is based on the search engine scanning headlines and newspaper reports. The scope and veracity of the data depends on several factors, such as the number of reports available online and how well any one report accurately reflects the events. Checking new headlines about past events, it is apparent that the aggregate data is often preliminary in nature. For example, later headlines reveal that an injured person has since succumbed. In other cases, and 
especially during major storm events, the number of incidents seems to be inaccurate, while later reports, sometimes years afterwards, provide a more balanced view; the fatalities and injuries were caused by factors other than trees falling on people.

Similarly, the level of detail reported is variable. In some cases, reports are sparse and no other headlines were detected to offer additional details. In other cases, the images or news video show type of failure and tree genus along with the names of the people affected, which allows for much better cross checking. With such variability, the data can only ever be used to derive order of magnitude estimates. And because the data were intended to show the relative seriousness of the problem, this variability is acceptable.

Six years of data are now in place and some trends are apparent. Most (but not all) incidents involve a wide range of adverse weather conditions, varying from gusty winds, heavy rain, and wind, through to hurricanes. While tree failures in extreme weather are highly likely, failures in less severe weather are also frequent. Using the data from the United States, the United Kingdom, Canada, and Australia, the most common type of incident is trees or tree parts falling on passing vehicles, such as cars, bicycles, motorbikes, ATVs, and snowmobiles ( 46\%), closely followed by pedestrians, horseback riders, or people outside in their yards $(\sim 40 \%)$. People inside buildings, (houses, mobile homes, barns) account for about $14 \%$ of incidents. Tree failures onto houses occur in most major storms but fatalities or injuries arising from the failure are less common. Electrocutions due to trees on power lines do occur, but not often. Incidents involving dead trees are common. Incidents involving trees with no obvious defects prior to failure are reported, but whether the tree would actually have passed a competent risk assessment before failure is less obvious. There have been several high-profile incidents in the United Kingdom dealing with this issue.

Overall, it is clear that the numbers are low. The six-year average (2008 to 2013) of deaths and inju- ries is shown in Table 1 (rounded to the nearest whole number). Note that the incidents recorded only involve people who were killed or injured. The headlines reviewed include many reports of trees falling down causing property damage, but within that data set, few tree failures cause death or injury. Major storms regularly bring down dozens if not hundreds of trees in any one event. But the exact number of trees that failed is almost never recorded. The data shown here only concerns fatalities and injuries. Note that the numbers of fatalities and injuries do not necessarily equal the number of incidents since there may have been more than one fatality and or injury per incident.

The results collected to date suggest that the magnitude of the problem is low as a percentage of national populations. The large-scale numbers are shown in Table 2 as likelihoods of being killed or injured within the six-year period documented.

In examining the articles and images in the documented reports, it is obvious that many incidents involved dead or seriously compromised trees within striking distance of well-used target zones. These trees could easily have been recognized and should have been removed or treated to reduce the risk levels. But not all incidents involved dead trees. Trees with clearly defined problems ought to be simple to recognize. Assessment by people who are trained in tree biomechanics and tree risk assessment protocols should help. But not all trees with defects will fail right away, and not all are automatic candidates for removal. And then there are tree failures where even the best risk assessor would not have had any reason to predict failure any time soon. Even the strongest trees fail when the conditions overwhelm them, and it would be unreasonable to expect otherwise.

While each event is undoubtedly of concern, does the general problem warrant large expenditures of time and money? The answer is not simple. A reasonable approach demands a response proportional to the problem. One the one hand, the costs of inaction or proven negligence are high, often sums

Table 1. Six-year averages.

\begin{tabular}{|c|c|c|c|c|c|c|c|c|}
\hline & $\begin{array}{l}\text { Tree } \\
\text { fatality }\end{array}$ & $\begin{array}{l}\text { Limb } \\
\text { fatality }\end{array}$ & $\begin{array}{l}\text { Total } \\
\text { fatalities }\end{array}$ & $\begin{array}{l}\text { Tree } \\
\text { injury }\end{array}$ & $\begin{array}{l}\text { Limb } \\
\text { injury }\end{array}$ & $\begin{array}{l}\text { Total } \\
\text { injuries }\end{array}$ & $\begin{array}{l}\text { Avg. no. } \\
\text { of incidents }\end{array}$ & $\begin{array}{l}\text { Total no. of incidents } \\
\text { in the six-year period }\end{array}$ \\
\hline Australia & 3 & 2 & 5 & 6 & 2 & 8 & 11 & 64 \\
\hline USA & 66 & 12 & 78 & 75 & 34 & 109 & 134 & 806 \\
\hline Canada & 2 & 2 & 4 & 3 & 0 & 3 & 5 & 32 \\
\hline UK & 5 & 1 & 6 & 13 & 2 & 15 & 18 & 111 \\
\hline
\end{tabular}


Table 2. Ratio of fatalities or injuries to population size ${ }^{z}$.

\begin{tabular}{llll}
\hline Country & Population & Fatalities & Injuries \\
\hline Australia & $22,262,501$ & 1 in 0.7 million & 1 in 0.4 million \\
USA & $316,438,601$ & 1 in 4 million & 1 in 3 million \\
Canada & $34,568,211$ & 1 in 11.5 million & 1 in 11.5 million \\
UK & $63,395,574$ & 1 in 10.5 million & 1 in 4 million \\
\multicolumn{2}{l}{ ㄷA Factbook (https://www.cia.gov/library/publications/the-world-fact- } \\
book/rankorder/2119rank.html).
\end{tabular}

that far outweigh the costs that would have been incurred by hiring additional trained staff. Court costs incurred in defending claims must surely be considerable. One the other hand, court verdicts in the United Kingdom and the United States seem to be leading toward a much greater degree of risk aversion for tree owners, an issue clearly seen in the United Kingdom after several high-profile incidents. But is tree removal regardless of risk level, a reasonable response when trees are known to confer so many desirable benefits? Certainly removal is a simple and tempting response. Whether or not it is good management is a different question.

Tree risk assessors now have broad guidance available, and risk assessment protocols are evolving as new knowledge becomes available. But it is also clear that there are many aspects where the science underpinning tree risk assessment is lacking, and not all of the existing science available is widely agreed upon around the world. The issue of acceptable shell wall thickness and strength loss is a good example (Rinn 2013). Better science and understanding should help to produce more reliable assessments. Tree risk assessors not only need to understand these technical aspects, but also be able to explain it to others, especially risk managers. For sure, tree risk assessors need to be well-versed in biomechanics and the assessment process. But, slavish adherence to a process or overly simplified data without clear understanding of the tree has led to a lot of unnecessary tree removals that could have been avoided with better knowledge. Conversely, some high-risk trees may have been missed simply because the importance of key evidence was not recognized. Better tree risk assessment skills may help to reduce the number of incidents.

Tree risk managers need to better understand the magnitude of the problem. Knee-jerk responses to every incident need to be tempered with better technical understanding. Risk managers need to recognize that due diligence requires a well- reasoned plan to assess and manage risk issues, balanced against tree benefits. Being aware of the tree inventory and having well-written policies to cope with changing tree conditions should be routine. Notwithstanding the often intense public and politicized debates about trees, managers need to be better able to defend their risk management strategies, whether that is retention with treatment, or removal.

Even so, the data collected so far clearly show that even with the best of intentions, some tree failures will always be unforeseeable. People will continue to be killed or injured in extreme weather events no matter have much risk assessment and risk management takes place.

\section{LITERATURE CITED}

Rinn, F. 2013. Shell-wall thickness and breaking safety of mature trees. Western Arborist 2014: 40-44.

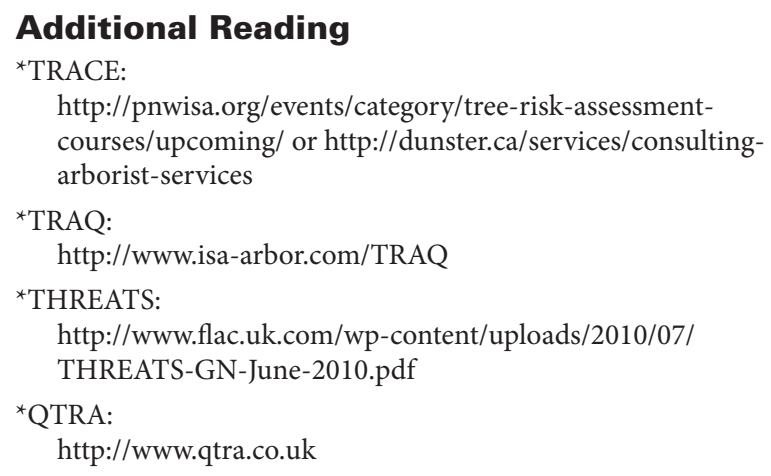

Julian Dunster

Principal author of the Tree Risk Assessment Manual

Victoria, British Columbia

Canada

http://dunster.ca 